\title{
The Symbolic Trend of Design in Consumer Society
}

\author{
Daijuan Yang \\ Sichuan University, Chengdu, Sichuan Province, China
}

Keywords: consumer society, modernist design, symbolic design, social responsibility.

\begin{abstract}
In the past, the essence of consumption was the relationship between people and objects. But in today's consumer society, it has become the symbolic interpersonal relationship established by objects, namely the symbolic consumption. Thus, symbolic design appears accordingly. Under this tendency of symbolic design, however, designers' social responsibility and the value of design are missing. Designers focus on making money in the ever changing environment, rather than serving clients who pursue for better life. Today, the value and significance of design should be re-examined and redefined, in order to revive the social responsibility of designers.
\end{abstract}

\section{Introduction}

Jean Baudrillard wrote following sentences in his book Consumer Society:

"We live in the time of objects; I mean we live according to their rhythms and the constantly replacing reality. In all past civilizations, objects can survive to later generations. Tools and buildings are enduring. But today, we see the production, improvement and wither of ourselves." [1]

Consumer society is the society surrounded by objects, and featured by the mass consumption of objects (commodities). The mass consumption of commodity not only changes people's daily life and basic necessities, but changes their basic attitudes towards the world and themselves.

\section{Symbolic Consumption}

According to the traditional view of political economy, consumption is the exchange of economic value and use value. In this sense, people can apprehend consumption behaviors as material practice, namely the purchase, possession and use of goods. Therefore, more attentions are paid on productions' physical characteristics, as well as their usage and practical values. When a society enters into consumption age, the social productive capacity goes far beyond the society's effective demands; surplus goods are produced. Under these circumstances, the basis of consumption is no longer commodities' using functions, but their symbolic functions of novelty, meaningfulness and communication. Therefore, Baudrillard believes in consumer society, consumption is the exchange of economic value and symbolic value. Today, we consume symbols, not goods. Symbolic values represent the differences between commodities. In the Consumer Society, Baudrillard wrote, "today, the circulation, purchase, sale and procession of differentiated wealth and goods /symbols constitute our language and code. The whole society relies on them to communicate." [2] Consumption has formed the foundation and bond of relationship among all members of the society.

The symbolization of consumption is a kind of deviation from commodities' use value. The real consumption becomes illusion consumption. In contemporary society, commercial advertising, newspapers, magazines, television, movies and other media cover the natural use value and relevant properties of products, and add new images and symbols to change the original meaning and usage conception of goods. They skillfully combine the commodity with cultural features like noble, elegant and romantic, and create all intentions which may not relate to the item. As a consequence, now we live in the intentional field of goods; the truth is disappearing. As Baudrillard said, we live in a simulacrum world today. We are surrounded by these simulacrum images as long as we consume. In such an imagery world, boundaries of true and false disappear; people do not reflect on the real world any more. Media provide us large quantity of public opinions, but people cannot separate the true 
from the false. They follow these produced hot issues willingly, and believe consumption freedom is the freedom to human life. They pursue consumption equality instead of human equality.

With the process of symbolic consumption, consumption is no longer the satisfaction of needs, but the satisfaction of evoked intentions. Debord called it as the satisfaction of pseudo needs. Therefore, consumption is becoming blind. People accept the consumption intention created by media without restraint; they pursue pleasure without restraint, and consider consumption as the way to realize their dream life. Today, consumption has controlled us, and our identities are based on identities and symbols created by media ideology. Just like Herbert Marcuse's analysis in One-Dimensional Man, today, with the process of technology, critical consciousness has become a sense of affirmation. People have lost their critical thinking.

\section{From Functional Design to Symbolic Design}

The greatest impact of symbolic consumption on design is the transformation from functional design to symbolic design. Functional design mainly refers to modernist design in the first half of the twentieth century. It is believed that modernist design brought great benefits to human society. Modernist design philosophy made designers public servants rather than salesmen. Modernists also believed they were leading the world to a better place.

This ideal of modernism can be traced to John Raskin (1819-1900) and William Morris (1834-1896). As the first socialist, Ruskin's design theory has obvious characteristics of democracy and socialism. He emphasized the democratic characteristics of design, advocating design for the mass public rather than elites. He said, "In the past, art is controlled by aristocracy's egoism. Its scope has never been expanded. It never makes people happy and helps them $\cdots$ Instead of producing luxury products, it's better to do something real." [3] Morris inherited Ruskin's theory and put it into practice; he sowed the seeds of modernism. The seed sprouted in the hands of Bauhaus, and finally led to the formation of modernist design.

The ideal of modernist design is embodied in its "functionalism". Although symbolic design in the pre modern era was based on functions, its purpose and functions lied in symbolism, rather than objective functions. It embodied the relationship between human beings, and had moral orientation. For example, the bourgeois furniture in classical times was designed on the basis of traditional and authoritative patriarchal relations. The furniture aimed to connect complex emotional relationships between family members. Modernist design pursued the expression of pure function. It removed symbolic decoration and liberated functions from moral constraints in the past. Therefore, in the modernist period, functions became the top issue of design; form was the natural result of function realization. Designers advocated simple, rational design; decorations were removed. They tried to realize the standardization and efficiency of production through the unification of art and modern technology. The functional design of standardization and efficiency lifted functionalism to a new level. It not only facilitated the usage of techniques, the updating of parts and the formation a broader regional service and support system, but greatly reduced cost, and offered people with equal rights to enjoy the design. Thus, modern design was democratic and egalitarian.

It can be seen from that, John Raskin, William Morris and Gropius wanted to transform the world and society through the combination of art and technology. Socialist characteristics can be found behind their design ideas. However, this ideal has vanished in the coming consumerism. In order to drive the development of consumption, design is effectively integrated into the economic development process. It deviates from its nature function gradually, and becomes the symbolic design.

The "streamlined" design sprang up in the United States in 1930s can be regarded as the beginning of symbolic design. The popularization of this kind of design promotes the development of product design, and shows the differences of product added by design. Design is used as a kind of operating resource. New appearance will make the existing products old. With the idea of "today's products will be out of date tomorrow", consumers' motivation is the purpose that all plans. In this process, design acts as the specific executor of plans. Cars, furniture, daily necessities, almost all products we can see 
emphasize their own value by constantly changing their modeling style, and thus control consumers' expectations.

Compared to the "streamlined" design, the Pop Design in 1960s has more features of symbolic design. At that time, some enterprises and designers began to respond directly to the needs of the public, and produced some consumer products which accorded with the emerging public values, in order to explore the symbolism and interests in design, and to expand the market among young people. These products focused on form expression and pure surface decoration; the concepts of modernism, like function and reasonable production, were left out. Pop Design emphasized flexibility and consumption, which means, the life of products should be transient like pop songs, in order to adapt the changing social and cultural conditions. In 1964, British designer Peter Murdoth designed a disposable chair for children. It was made from cardboard and decorated with patterns. At the same time, paper earrings, bracelets even paper clothing came into fashion. Paul Clark designed a series of temporary pop consumer goods in the same year, including clocks, bowls, gloves and small accessories. Clark used the Union flag pattern on all these products, regardless of their functions. The focus of Pop Design was surface pattern; designers emphasized the temporary sense and the sense of humor. This series of products became a sign of London rock bands in the mid - 1960s, and were sold in some stores. It can be seen that, Pop Design enriched the semantic meaning of products, and paid more attention to the cultural context of contemporary consumer society. However, this essentially reflected that in the increasingly diversified market, monopoly capitalists encouraged consumers to buy products, in order to satisfy their own interests. They emphasized personalities and strange performances in design. The culture was fundamentally different from the symbolic culture in pre industrial era. It was superficial and regarded popular consumption as its ultimate goal. Culture became a commodity, which was an important step towards the symbolization of design.

From the "streamlined" design style to Pop Design, it is not difficult to see the through the changing style, designers tried to meet people's psychological needs of pursuing differences caused by material growth. But this kind of promotion was not the real symbolic consumption. In 1980s, postmodernism designers did not indulge in designing styles any longer; they started to create a set of imaginary symbol system from their own experience, and make design like a kind of play. "Brand" is the concentrated expression of this fictional symbol system. It is a systematic operational behavior that helps people to identify and realize the symbolic value of things. As the extension or "signifier" of products, brand has replaced products as the object of consumption, and helped consumers to achieve the leap from possession of specific items to worship of virtual goods. In essence, brands are mature cultural codes in the consumer society. French marketing scholar, Kim Carver analyzed the features of brands, and found that in the early stage all brands were ordinary; but after a period of time, some brands created their own contents. At first, brands attach meaningless words to a new product; then meanings are created after years. These meanings are composed of communication and products in consumers' memory, and explain things that can be and cannot be understood. Therefore, the contents of brand can be regarded as the "imaginary community" built by all participants. Hereto, design has become completely symbolic, and entered the consumption logic of consumer society. The goal of design is to achieve its symbolic value.

\section{The Value Crisis under the Trend of Symbolic Design}

In the consumer society, the symbolization of design is mainly represented as the molding of class symbols, personality symbols and fashion symbols. They excessively amplify people's psychological needs; their real demands are hided. "Function" stands behind spiritual symbols like "identity" "status" and "taste". This kind of design deviates from the essence of design. What the designers are doing is publicizing consumerism in the capitalist dominated environment.

From the functional design to symbolic design, designers actually follow the logic of consumerism, and gradually deviate from their initial commitment to people. Today, as Deyan Sudjic points in The Language of Things, "design does not serve for better lives any longer. Designers focus on making money in the ever changing environment. From one perspective, the ideal design and improvement revealed in the 'The Arts and Crafts Movement' led by William Morris in the second half of 
nineteenth century, the movement created by faculty of the Bauhaus, and old designers' motivation of keep improving during World War II, were all wiped out in the commercial trend of contemporary society." [4]

Victor Papanek use three triangular schemata to illustrate today's design. If we consider one triangle as the "design problem", we will find that designers only concern the small top part of this triangle. If we take the triangle as the "state" and "the world", we will find that designers serve only a small group of people. Design belongs to a small circle of luxury; most people in the country or the world cannot truly enjoy changes brought by design. Designers always concern the small top part of this triangle; they ignore the real needs of people. So, what are the real needs of people? Papanek lists a lot of safety accidents caused by unreasonable design, such as unsafe "safety helmets", remote taxis which would cause substantial damage to driver's knees, toys threatening children's safety and health... Today, there are many questions waiting to be solved by good design. As a designer, what is the true value of design is a problem worth thinking.

\section{References}

[1] J. Baudrillard. Consumer Society, C.F. Liu, Z.G. Quan (Trans.), Nanjing University Press, Nanjing, 2001.

[2] G. Luo, Z.Z. Wang, Consumer Culture Reader, China Social Sciences Press, Beijing, 2003.

[3] S.Z. Wang, Modern Design History, New Century Publishing House, Beijing, 2001.

[4] D. Sudjic, The Language of Things, J. Zhuang (Trans.), Rover Co. Limited Company, Taipei, 2009. 